\title{
Transit-time flow characteristics of in situ right gastroepiploic arterial grafts in coronary artery bypass grafting
}

\author{
Yoshiyuki Takami, MD, Kazuyoshi Tajima, MD, Sachie Terazawa, MD, Noritaka Okada, MD, \\ Kei Fujii, MD, and Yoshimasa Sakai, MD
}

Objective: We investigated flow characteristics of right gastroepiploic arterial grafts, widely used to extend in situ arterial conduits in coronary artery bypass grafting.

\begin{abstract}
Methods: Intraoperative transit-time measurements and postoperative angiographic findings were obtained for 111 patients undergoing coronary artery bypass grafting with gastroepiploic artery and bilateral internal thoracic arteries: mean, maximum, and minimum flows; pulsatility index; insufficiency rate; and differentiated index of early diastolic flow.
\end{abstract}

\begin{abstract}
Results: Favored target for gastroepiploic artery was posterior descending artery (106 patients, $95 \%$ ). Patency rates were $91.0 \%$ for gastroepiploic artery, $98.2 \%$ for left internal thoracic artery, and $97.5 \%$ for right internal thoracic artery. There were four flow profiles of gastroepiploic arteries: A (systolic protruded), B (trapezoidal), C (sine waved), and D (diastolic-dominant biphasic). Functional gastroepiploic arteries showed A in 16 cases, B in $6, \mathrm{C}$ in 31 , and $\mathrm{D}$ in 48 , with prevalence according to severity of stenosis in target coronary artery. Two occluded gastroepiploic arteries showed type A, and reverse or competitive flows were types A in 1, B in 1, C in 4, and D in 2. Relative to functional internal thoracic arteries, functional gastroepiploic arteries showed significantly lower minimum flow, higher insufficiency rate, and lower differentiated index of early diastolic flow.

Conclusion: Intraoperative transit-time flow profiles of patent in situ gastroepiploic arterial grafts were classified into four types, closely associated with disease severity of target coronary artery. Patent in situ gastroepiploic arterial grafts show more regurgitant flow and lower differentiated index of early diastolic flow than in situ internal thoracic arterial grafts.
\end{abstract}

The current trend in coronary artery bypass grafting (CABG) is toward total in situ arterial grafting. This trend is a response to previous studies demonstrating that the greater number of in situ arterial conduits used, the better are long-term outcomes. ${ }^{1,2}$ In the strategy of total in situ arterial CABG, the right gastroepiploic artery (GEA) is used as a third conduit, in addition to bilateral internal thoracic arteries (ITAs) for the left coronary system. ${ }^{3,4}$ Although there is no evidence that using an arterial graft to the right coronary artery (RCA) or its branches confers patient benefit, logic would dictate that if a GEA graft is more likely to remain patent than is a saphenous vein graft, this should confer some patient benefit. Although the early patencies are comparable, the longterm patency of GEA grafts is inferior to that of ITA grafts anastomosed to the left coronary artery system. ${ }^{5,6}$ This difference in patency between the GEA and the ITAs may result not only from differences in target coronary vessels but also from

\footnotetext{
From the Department of Cardiovascular Surgery, Nagoya Daini Red Cross Hospital, Nagoya, Japan.

Received for publication Sept 2, 2008; revisions received Dec 22, 2008; accepted for publication Feb 1, 2009; available ahead of print April 3, 2009.

Address for reprints: Yoshiyuki Takami, MD, Department of Cardiovascular Surgery, Nagoya Daini Red Cross Hospital, 2-9 Myouken-cho, Showa-ku, Nagoya 466-8650 Japan (E-mail: takami@nagoya2.jrc.or.jp).

J Thorac Cardiovasc Surg 2009;138:669-73

$0022-5223 / \$ 36.00$

Copyright (c) 2009 by The American Association for Thoracic Surgery

doi:10.1016/j.jtcvs.2009.02.011
}

difference in the properties of the conduit flow itself. Flow characteristics of the GEA and hemodynamic differences in these arterial conduits have not been fully understood. To reveal the specific properties of the GEA as an in situ conduit, we investigated flow characteristics by means of intraoperative transit-time flow measurement.

\section{MATERIALS AND METHODS \\ Study Patients and CABG}

From January 2004 to December 2006, a total of 125 consecutive patients underwent all in situ arterial CABG exclusively with left ITA and GEA with or without right ITA. They comprised $46 \%$ of all patients undergoing $\mathrm{CABG}$ in our institution. Of these patients, we enrolled 111 (90 men and 21 women, mean age $63 \pm 8$ years) in the study. Participants underwent both intraoperative flow analysis and postoperative angiography within 1 month after surgery. The study patients underwent isolated CABG ( $\mathrm{n}=104$ ) or CABG plus combined procedures, including mitral valve plasty $(n=3)$, aortic valve replacement $(n=2)$, and left ventricular reconstruction $(\mathrm{n}=2)$. The isolated CABG were performed either with cardiopulmonary bypass $(n=53,54 \%)$ or without $(n=51,46 \%)$ in the standard manner. The patient characteristics are summarized in Table 1.

In our strategy, in situ bilateral ITAs were preferred for revascularization of the left coronary territory whenever possible anatomically. The right ITA was used to revascularize the left anterior descending artery by crossing the midline if necessary. Diabetes mellitus, advanced age, and left ventricular dysfunction were not considered to be contraindications; however, the use of bilateral ITAs was avoided in the patients with diabetes who were undergoing hemodialysis. The GEA was mostly used for revascularization of the RCA territory with more than $75 \%$ stenosis. The use of GEA was avoided when significant narrowing or calcification of the celiac axis was found on 


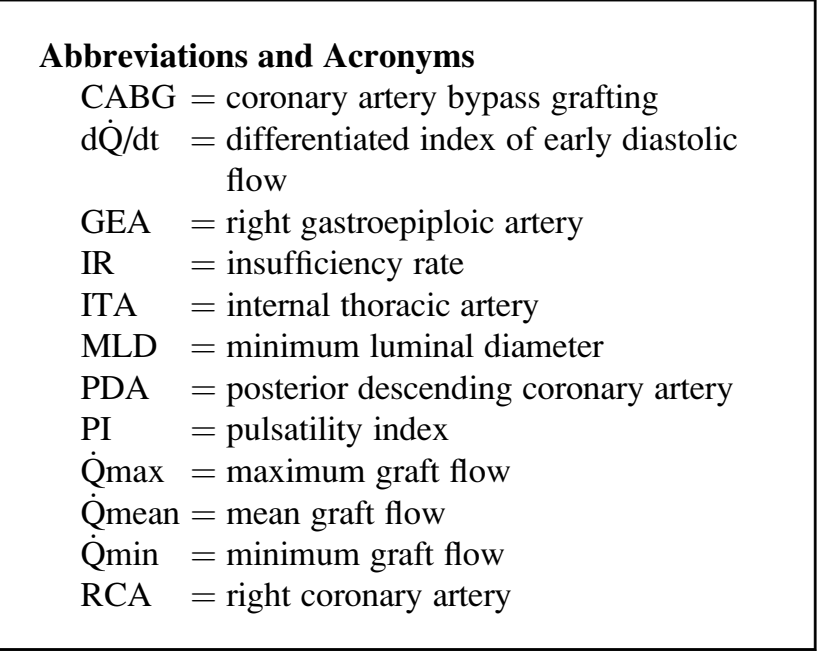

preoperative computed tomography, when the diameter of the GEA at the anastomosis site was smaller than $2.0 \mathrm{~mm}$, or when the palpable atheroma was present.

The ITA was completely skeletonized with an ultrasonic scalpel (Harmonic Scalpel; Ethicon Endo-Surgery, Cincinnati, Ohio), as previously reported, ${ }^{7}$ and was harvested from the bifurcation of the musculophrenic and superior epigastric arteries up to the upper margin of the first rib or higher. The GEA was also harvested with the Harmonic Scalpel with a coagulating shears tip, as previously reported. ${ }^{8,9}$ The anterior layer of the greater omentum was incised throughout the necessary graft length. Then the small omental and gastric branches of the GEA were divided. Consequently, the GEA was harvested either with satellite veins (semiskeletonized) or without veins (completely skeletonized). After systemic heparinization, the distal ends of the ITAs and GEA were divided, diluted solutions of olprinone hydrochloride (INN; Eisai Co, Ltd, Tokyo, Japan) were infused intraluminally, and all grafts were wrapped with papaverinesoaked sponges. All coronary anastomoses were constructed with 7-0 polypropylene (Nespilene; Alfresa Pharma Corp, Osaka, Japan). This retrospective study was approved by the institutional review board of our hospital, and written, informed consent was obtained from each patient before the surgery and postoperative angiography.

\section{Intraoperative Flow Measurements}

Graft flow tracings were obtained intraoperatively with a transit-time flowmeter (BF 2000; Medi-Stim AS, Oslo, Norway). A flow probe of 2 or $3 \mathrm{~mm}$ was placed around the distal portion of the graft body when the hemodynamic condition became stable with a mean blood pressure between 70 and $90 \mathrm{~mm} \mathrm{Hg}$ at a rectal temperature greater than $36.0^{\circ} \mathrm{C}$ before chest closure. With a semiskeletonized GEA, we divided a part of the GEA from the vein for probe placement to avoid graft constriction by the probe. On the basis of the obtained flow profile, the following variables were calculated: mean graft flow (Q்ean, in milliliters per minute), maximum graft flow (Q்max, in milliliters per minute), minimum graft flow ( $\dot{\mathrm{Q} m i n}$, in milliliters per minute), pulsatility index (PI, calculated as [نंmax - $\dot{\mathrm{Q} m i n}] /$ Qmean), insufficiency rate (IR, calculated as the volume of backward flow divided by the volume of forward flow and expressed as a percentage),

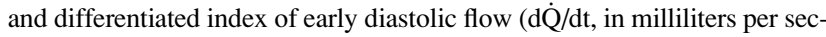
ond squared), as shown in Figure 1.

\section{Postoperative Angiography}

Every study patient underwent cardiac catheterization within 1 month after CABG with a standard technique through the femoral or brachial route. All grafts were examined from at least two different views. The angiograms
TABLE 1. Characteristics of the study patients

\begin{tabular}{lc}
\hline No. of patients & 111 \\
Age (y, mean \pm SD) & $63 \pm 8$ \\
Sex (male/female) & $90: 21$ \\
Smoking (no.) & $60(54 \%)$ \\
Hyperlipidemia (no.) & $68(61 \%)$ \\
Hypertension (no.) & $69(62 \%)$ \\
Diabetes mellitus (no.) & $56(50 \%)$ \\
Insulin therapy (no.) & $19(17 \%)$ \\
Serum creatinine (mg/dL, mean \pm SD) & $1.6 \pm 2.2$ \\
Long-term hemodialysis (no.) & $6(5 \%)$ \\
History of heart failure (no.) & $42(38 \%)$ \\
Previous myocardial infarction (no.) & $62(56 \%)$ \\
Left ventricular ejection fraction $(\%$, mean \pm SD) & $56 \% \pm 24 \%$ \\
Coronary artery bypass grafting & \\
$\quad$ Conventional (no.) & $39(35 \%)$ \\
$\quad$ Cardiopulmonary bypass (min, mean \pm SD) & $159 \pm 33$ \\
$\quad$ Aortic crossclamp (min, mean \pm SD) & $106 \pm 22$ \\
$\quad$ On pump, heart beating (no.) & $21(19 \%)$ \\
$\quad$ Off pump (no.) & $51(46 \%)$ \\
Anastomoses (mean \pm SD) & $3.5 \pm 1.1$ \\
\hline
\end{tabular}

were independently reviewed by two or more cardiologists and resolved by consensus. Graft patency was scored as 0 for an occluded graft, as 1 for reverse graft flow or when the flow from the native coronary artery was dominant, as 2 for competitive graft flow or when flow supplies from the native coronary and from the graft were balanced, and as 3 for a functional graft or when the native coronary was fully opacified by the graft. A graft was considered nonfunctional at patency scores of 0 to 2 .

\section{Statistical Analysis}

Analysis was performed with Excel 2000 (Microsoft Corp, Redmond, Wash) and StatView 5.0 (SAS Institute, Inc, Cary, NC). All data were expressed as means $\pm \mathrm{SD}$. For multiple group comparisons, we used analysis of variance of the averages. Significances of individual differences were evaluated by using the Scheffé test if the result of analysis of variance was significant.

\section{RESULTS}

The study patients received a total of 402 distal anastomoses, with an average of $3.5 \pm 1.1$ anastomoses per patient. There were no in-hospital deaths among the study patients. The in situ GEA was anastomosed to the posterior descending coronary artery (PDA) off the RCA in 106 patients $(95 \%)$, the main RCA in 3, the left circumflex artery in 1, and the left anterior descending coronary artery in 1 . The GEA grafts to the PDA included three types of sequential grafts: main RCA to PDA $(n=1)$, PDA to posterior lateral branch of RCA ( $n=17)$, PDA to left circumflex artery $(n=5)$, and PDA to posterior lateral branch of RCA to left circumflex artery $(n=3)$. The atherosclerotic disease of the target coronary arteries of GEAs showed total occlusion in 41 cases, severe stenosis $(>90 \%)$ in 50 , and moderate stenosis $(75 \%-90 \%)$ in 10 . When there were more than two lesions with $75 \%$ stenosis, we considered the lesion to be severely stenosed.

According to postoperative angiography, 101 of 111 GEA grafts $(91.0 \%), 109$ of 111 left ITA grafts $(98.1 \%$, including 


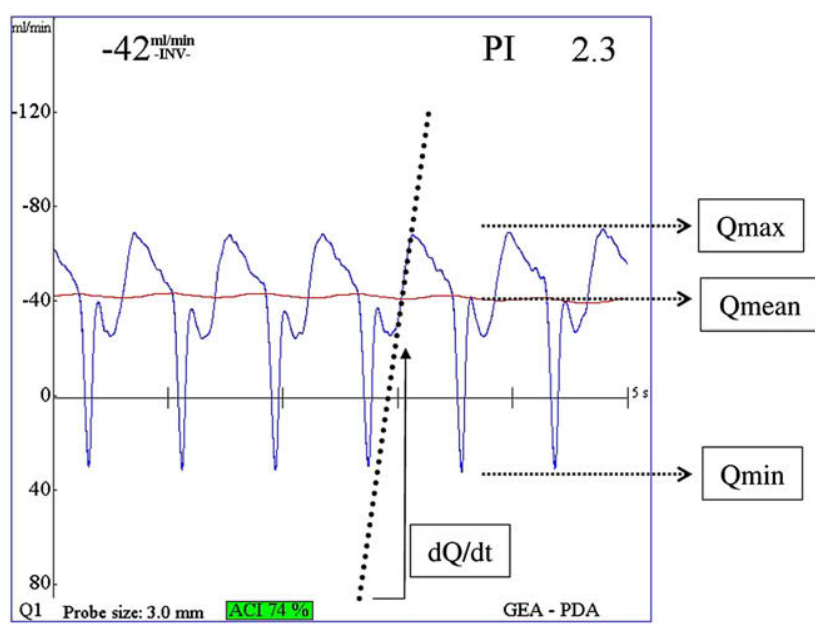

FIGURE 1. Parameters of intraoperative transit-time flow analysis. Calculated variables are mean graft flow (Qmean, in milliliters per minute), maximum graft flow (Qmax, in milliliters per minute), minimum graft flow $(Q m i n$, in milliliters per minute), pulsatility index (PI, derived as [Qmax Qmin]/Qmean), insufficiency rate (IR, volume of backward flow divided by volume of forward flow, expressed as percentage), and differentiated index of early diastolic flow ( $d Q / d t$, in milliliters per second squared).

37 sequential grafts), and 79 of 81 right ITA grafts (97.5\%, including 26 sequential grafts) were patent and functional. Ten nonfunctional GEA grafts demonstrated occlusion (score 0 ) in 2 cases, reverse flow (score 1) in 5, and competitive flow (score 2) in 3 . All nonfunctional GEA grafts were GEAs with single anastomosis ( $\mathrm{n}=8$ to PDA, $\mathrm{n}=2$ to posterior lateral branch of RCA). Comparisons of intraoperative transit-time flow data between the functional GEAs and ITAs are shown in Table 2. The functional GEAs and ITAs demonstrated similar values of Qmean, Qmax, and PI; however, the functional GEAs showed significantly lower Qmin, higher IR, and lower dQ $/ \mathrm{dt}$ than did the functional ITAs. The $\dot{\mathrm{Q} m e a n}$
TABLE 2. Comparison of transit-time flow data among functional, patent in situ arterial grafts

\begin{tabular}{lccr}
\hline & $\begin{array}{c}\text { GEA } \\
(\mathbf{n}=\mathbf{1 0 1})\end{array}$ & $\begin{array}{c}\text { LITA } \\
(\mathbf{n}=\mathbf{1 0 9})\end{array}$ & \multicolumn{1}{c}{$\begin{array}{c}\text { RITA } \\
(\mathbf{n}=\mathbf{7 9})\end{array}$} \\
\hline Mean flow (mL/min) & $32 \pm 18$ & $36 \pm 18$ & $35 \pm 19$ \\
Maximum flow (mL/min) & $64 \pm 30$ & $64 \pm 29$ & $68 \pm 17$ \\
Minimum flow (mL/min) & $-15 \pm 22^{*}$ & $! 5 \pm 16$ & $! 6 \pm 17$ \\
Pulsatility index & $2.8 \pm 1.6$ & $2.1 \pm 0.9$ & $2.4 \pm 1.3$ \\
Insufficiency rate (\%) & $4.4 \pm 7.0^{*}$ & $1.7 \pm 3.5$ & $1.9 \pm 3.4$ \\
$\begin{array}{l}\text { Differentiated index } \\
\quad \text { of early diastolic } \\
\text { flow (mL/s }{ }^{2} \text { ) }\end{array}$ & $7.4 \pm 4.1 *$ & $11.2 \pm 5.2$ & $13.0 \pm 6.3$ \\
$\begin{array}{l}\text { GEA, Right gastroepiploic artery; } \text { LITA, left internal thoracic artery; RITA, right inter- } \\
\text { nal thoracic artery. } * P<.01 .\end{array}$ &
\end{tabular}

values of functional GEA grafts were significantly larger in patients with sequential anastomoses than in patients with single anastomoses $(37 \pm 20 \mathrm{~mL} / \mathrm{min}$ vs $28 \pm 16 \mathrm{~mL} / \mathrm{min}$, $P=.03)$.

The intraoperative transit-time flow profiles of GEAs were classified into four types, as shown in Figure 2: A, systolic protruded; B, trapezoidal; C, sine-waved; and D, diastolic-dominant biphasic. The functional GEAs showed type $\mathrm{A}$ in 16 cases, type $\mathrm{B}$ in 6 , type $\mathrm{C}$ in 31 , and type $\mathrm{D}$ in 48. The distributions of these types of flow profiles are demonstrated in Figure 3, grouped by the disease severity of the native coronary artery to be grafted. Most GEAs anastomosed to the totally occluded coronary arteries showed flow profiles of type D. When the native coronary lesions were mild, most GEAs showed flow profiles of type C. Among the nonfunctional GEAs, both occluded GEAs showed type A, as shown in Table 3, with Qmean values significantly lower than those of functional GEAs with type A flow. Five GEAs with reverse flow showed type B in 1 case, type $\mathrm{C}$ in 3 , and type $\mathrm{D}$ in 1 . Three GEAs with competitive flow showed type $\mathrm{A}$ in 1 case, type $\mathrm{C}$ in 1 ,
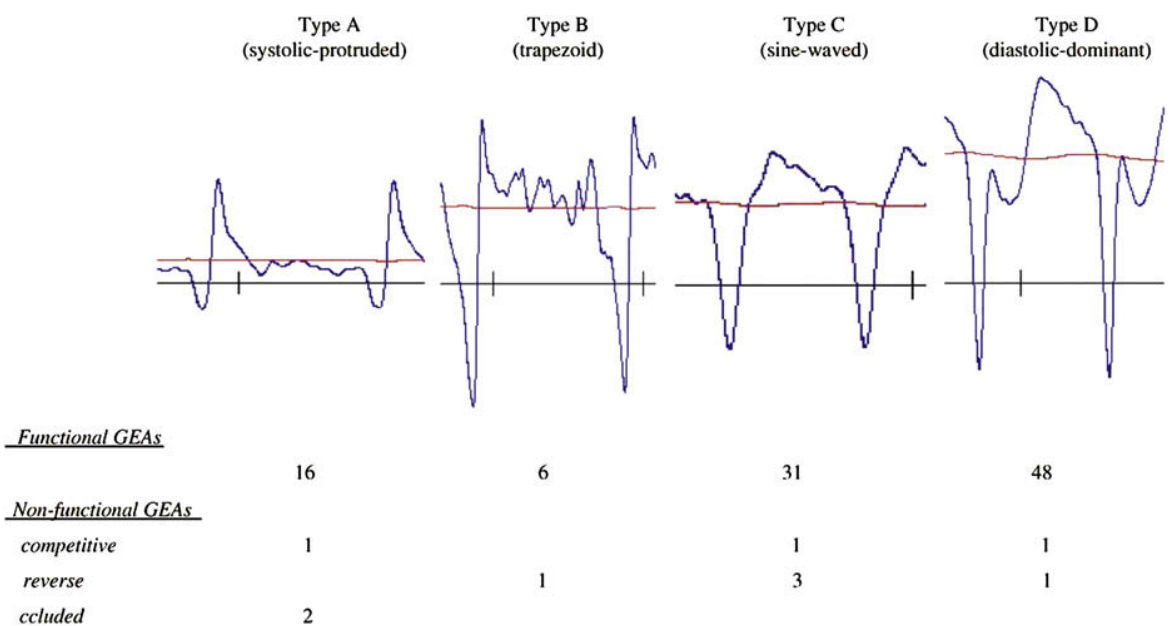

FIGURE 2. Four types of intraoperative transit-time flow profiles of in situ right gastroepiploic arteries $(G E A s)$ : $A$, systolic protruded, $B$, trapezoidal, $C$, sinewaved, and $D$, diastolic-dominant biphasic. Distributions of these types in functional and nonfunctional gastroepiploic artery grafts. 

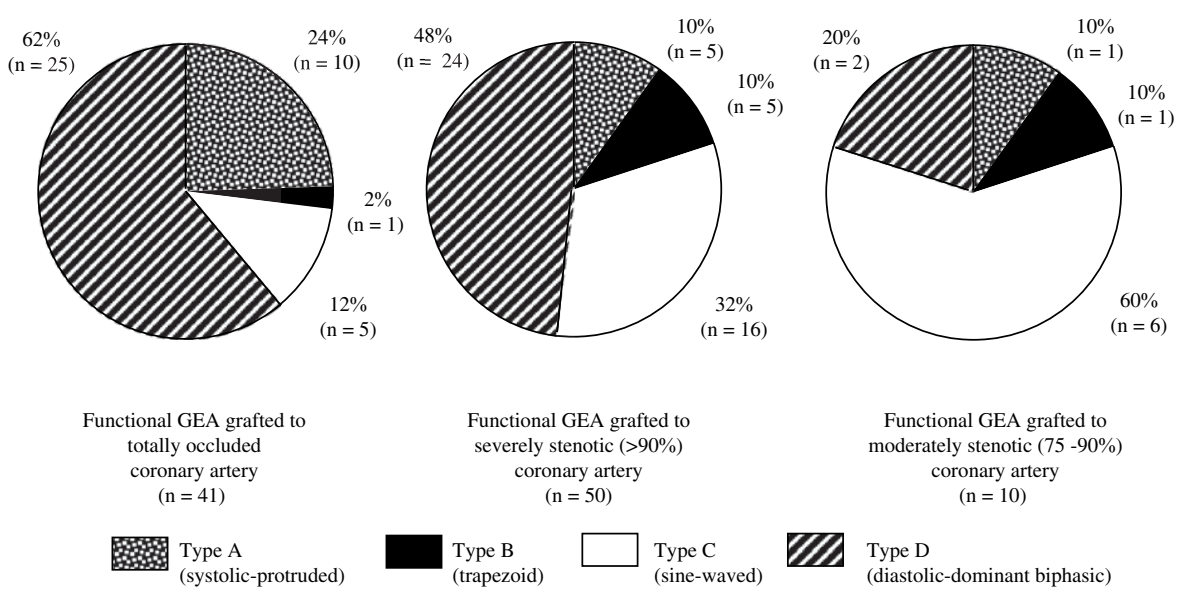

FIGURE 3. Distributions of four types of intraoperative transit-time flow profiles of in situ right gastroepiploic arteries (GEAs) according to disease severity of native coronary artery to which functional gastroepiploic artery was grafted.

and type D in 1. Among the functional GEAs, the Qmean values were significantly larger in types $C$ and $D$ than in types A and B. The PI values of functional GEAs with type A flow were significantly larger than those with other types. The IR values of functional GEAs wirh type $\mathrm{C}$ flow were significantly larger than those with other types.

\section{DISCUSSION}

A few studies have used Doppler echocardiography to examine flow characteristics of in situ GEA grafts. ${ }^{10-12}$ We applied intraoperative transit-time flow analysis in this study. Although several transit-time flow studies of CABG grafts have been published, ${ }^{13-15}$ there have been no studies focusing on the flow characteristics of in situ GEA grafts in a large number of patients. The main findings of our study were fourfold: (1) Intraoperative transit-time flow profiles of the functional in situ GEA grafts were variable and could be classified into four types as systolic protruded, trapezoidal, sine-waved, and diastolic-dominant biphasic. (2) These types were closely associated with the disease severity of the target coronary artery to be grafted. (3) Among these types, the protruded type was unique to GEA and suggested graft failure when the Qmean is low. (4) The patent in situ GEA grafts to the RCAs showed more regurgitant flow and lower dQ $/$ dt than in situ ITA grafts to the left coronary arteries.

Louagie and associates ${ }^{10}$ demonstrated that the GEA was characterized by a higher maximum trace velocity, a higher dispersion of velocity spectra, and a wide range of velocities. These characteristic waveforms of the GEA can be explained by the wall structure of the graft (elasticity, compliance), by the length, and by the increased time delay between ventricular systole and arrival of the pulse wave into the coronary artery. Travilla and colleagues ${ }^{11}$ showed the quite variable extent of the myocardial territory supplied by the GEA and therefore speculated that baseline flow may vary significantly among GEAs. These previous findings coincide with our results that functional GEA grafts show various flow profiles, which we classified into four types. In addition, Shimizu and associates ${ }^{12}$ revealed that the transition between systole and diastole in velocity spectra was obscure in the GEA, whereas typical biphasic velocity spectra were observed in

TABLE 3. Distributions of four flow profile types (A, B, C, D) and transit-time flow data for functional and nonfunctional in situ gastroepiploic arterial grafts

\begin{tabular}{|c|c|c|c|c|c|c|c|c|}
\hline & \multicolumn{4}{|c|}{ Functional } & \multicolumn{4}{|c|}{ Nonfunctional } \\
\hline & $\mathbf{A}$ & B & C & D & $\mathbf{A}$ & B & C & D \\
\hline No. & 16 & 6 & 31 & 48 & 3 & 1 & 4 & 2 \\
\hline Competitive & - & - & - & - & 1 & - & 1 & 1 \\
\hline Reverse & - & - & - & - & - & 1 & 3 & 1 \\
\hline Occluded & - & - & - & - & 2 & - & - & - \\
\hline Mean flow (mL/min) & $20 \pm 7$ & $23 \pm 14$ & $34 \pm 9^{*}$ & $36 \pm 19 *$ & $8 \pm 1$ & 8 & $17 \pm 18$ & $12 \pm 4$ \\
\hline Pulsatility index & $4.3 \pm 1.6 \dagger$ & $2.1 \pm 0.5$ & $3.1 \pm 2.1$ & $2.3 \pm 1.0$ & $8.5 \pm 10.0$ & 3.7 & $10.7 \pm 10.7$ & $4.4 \pm 2.6$ \\
\hline Insufficiency rate $(\%)$ & $4.0 \% \pm 3.2 \%$ & $1.0 \% \pm 1.7 \%$ & $8.5 \% \pm 10.5 \% \ddagger$ & $2.4 \% \pm 4.0 \%$ & $12.2 \% \pm 20.1 \%$ & $6.9 \%$ & $31.4 \% \pm 30.8 \%$ & $12.2 \% \pm 12.7 \%$ \\
\hline
\end{tabular}

Values are mean \pm SD. *Among functional gastroepiploic arteries, flow values were significantly larger in types $\mathrm{C}$ and $\mathrm{D}$ than in types A and B $(P<.05)$. $\nmid \mathrm{Pulsatility}$ index values of functional type A gastroepiploic arteries were significantly larger than those of other types $(P<.05)$. ఫ̇nsufficiency rate values of functional type $\mathrm{C}$ gastroepiploic arteries were significantly larger than those of other types $(P<.05)$. 
the ITAs. These characteristics were also demonstrated in our study. As shown in Figure 3, the distribution of the types of GEA flow profiles varies according to the severity of stenosis of the target coronary artery to be grafted. When the GEA is grafted to a totally occluded coronary artery, it is likely that the flow profile is diastolic-dominant biphasic (type D). When the GEA is grafted to a coronary artery with moderate stenosis, resulting in competitive flow, it is likely that the flow profile is sine-waved (type C) with a higher IR value, suggesting obscure transition between systole and diastole. Among the types of flow profiles, the systolic protruded type (type A) with a higher PI value is observed irrespective of the severity of the target coronary lesions. Although this type may be unique to the GEA grafts with higher maximum trace velocity, stenosis or occlusion is suggested when the Qmean is low $(<15 \mathrm{~mL} / \mathrm{min})$.

This study also demonstrated differences in flow profiles between the ITAs and GEA, even though the perfused areas were different. There are several anatomic and physiologic differences between the two conduits; however, differences in flow characteristics between the GEA and ITA are not fully understood. An experimental study ${ }^{16}$ revealed that when grafted to the coronary artery with lower grade stenosis, the GEA exhibits more competitive flow than does the ITA. This may result from lower driving pressure of the GEA, associated with longer anatomic distance from the aortic root. These characteristics may account for our results of more regurgitant flow and lower dQ/dt for the GEA to RCA than for in situ ITA grafts to the left coronary arteries, although we did not strictly investigate the effects of runoff bed, especially in sequential grafting.

One of the limitations of this study is that we did not pay attention to the luminal diameter of the target coronary artery of the GEA. Glineur and colleagues ${ }^{17}$ investigated the preoperative angiographic variables that could influence 6-month graft patency and flow pattern. In their multivariate analysis, graftdependent flow pattern was significantly associated with the minimum luminal diameter (MLD) of the RCA in the GEA group. The GEA patency increased as MLD decreased. When the MLD of the RCA was 0 (100\% stenosed), all GEA grafts were patent, whereas when it was greater than $1.4 \mathrm{~mm}$, only $5 \%$ were functioning. They suggested that MLD rather than maximum percentage of stenosis should be used as a surrogate for competitive flow. Another limitation of this study is that we did not measure the sizes of GEA grafts, either intraoperatively or postoperatively. GEA grafts vary in size, and the size variation may affect flow patterns. Although intraoperative size measurements may be inaccurate because of GEA spasm, we should have evaluated the size of GEA postoperatively with quantitative angiography. Furthermore, we did not examine the lengths of the GEA grafts, the distal quality of the coronary artery grafted, and the myocardial viability of the territory revascularized, all of which influence GEA flow. It appears possible, however, that distal perfusion area is closely related to GEA flow, as suggested by our finding that $\dot{Q}$ mean values of functional GEA grafts were significantly larger in sequential anastomoses and that all the nonfunctional GEA grafts were GEAs with single anastomoses, not with sequential bypass.

In conclusion, intraoperative transit-time flow profiles of the functional in situ GEA grafts were variable and could be classified into four types, closely associated to the disease severity of the target coronary artery. Among these types, the protruded type is unique to GEA and suggests graft stenosis or occlusion when the Qmean is low. The patent in situ GEA grafts to RCAs in particular showed more regurgitant flow and lower dQ $/$ dt than did in situ ITA grafts to the left coronary arteries. These findings may help surgeons to judge the anastomosis quality of the in situ GEA graft in the operating room.

\section{References}

1. Lytle BW, Blackstone EH, Loop FD, Houghtaling PL, Arnold JH, Akhrass R, et al. Two internal thoracic artery grafts are better than one. J Thorac Cardiovasc Surg. 1999;117:855-72.

2. Taggart DP, D'Amico R, Altman DG. Effect of arterial revascularisation on survival: a systematic review of studies comparing bilateral and single internal mammary arteries. Lancet. 2001;358:870-5.

3. Nishida H, Tomizawa Y, Endo M, Koyanagi H, Kasanuki H. Coronary artery bypass with only in situ bilateral internal thoracic arteries and right gastroepiploic artery. Circulation. 2001;104(12 Suppl. 1):I76-80.

4. Nishida H, Tomizawa Y, Endo M, Kurosawa H. Survival benefit of exclusive use of in situ arterial conduits over combined use of arterial and vein grafts for multiple coronary artery bypass grafting. Circulation. 2005;112(9 Suppl):I299-303.

5. Malvindi PG, Jacob S, Kallikourdis A, Vitale N. What is the patency of the gastroepiploic artery when used for coronary artery bypass grafting? Interact Cardiovasc Thorac Surg. 2007;6:397-402.

6. Suma H, Tanabe H, Takahashi A, Horii T, Isomura T, Hirose H, et al. Twenty years experience with the gastroepiploic artery graft for CABG. Circulation. 2007;116(11 Suppl):I188-91.

7. Higami T, Yamashita T, Nohara H, Iwahashi K, Shida T, Ogawa K. Early results of coronary grafting using ultrasonically skeletonized internal thoracic arteries. Ann Thorac Surg. 2001;71:1224-8.

8. Asai T, Tabata S. Skeletonization of the right gastroepiploic artery using an ultrasonic scalpel. Ann Thorac Surg. 2002;74:1715-7.

9. Suma H, Tanabe H, Yamada J, Mikuriya A, Horii T, Isomura T. Midterm results for use of the skeletonized gastroepiploic artery graft in coronary artery bypass. Circ J. 2007;71:1503-5.

10. Louagie YA, Jamart J, Buche M, Eucher P, van San P, Theys S, et al. Intraoperative hemodynamic assessment of gastroepiploic artery and saphenous vein bypass grafts: a comparative study. J Thorac Cardiovasc Surg. 1999;118:330-8.

11. Tavilla G, Pijls NH, Peels KH, Berreklouw E. Noninvasive assessment of coronary flow reserve in the right gastroepiploic artery graft. Ann Thorac Surg. 2000;70:2040-4

12. Shimizu T, Suesada H, Cho M, Ito S, Ikeda K, Ishimaru S. Flow capacity of gastroepiploic artery versus vein grafts for intermediate coronary artery stenosis. Ann Thorac Surg. 2005;80:124-30.

13. Takami Y, Ina H. Relation of intra-operative flow measurement with post-operative quantitative angiographic assessment of coronary artery bypass grafting. Ann Thorac Surg. 2001;72:1270-4.

14. Leong DK, Ashok V, Nishkantha A, Shan YH, Sim EK. Transit-time flow measurement is essential in coronary artery bypass grafting. Ann Thorac Surg. 2005;79:854-7.

15. Tokuda Y, Song MH, Ueda Y, Usui A, Akita T. Predicting early coronary artery bypass graft failure by intraoperative transit time flow measurement. Ann Thorac Surg. 2007;84:1928-33.

16. Iida Y, Obitsu Y, Shigematsu H. Flow dynamic comparison of in-situ internal thoracic and gastroepiploic arterial conduits: experimental study. Jpn J Thorac Cardiovasc Surg. 2006;54:233-8.

17. Glineur D, D'hoore W, El Khoury G, Sondji S, Kalscheuer G, Funken JC, et al. Angiographic predictors of 6-month patency of bypass grafts implanted to the right coronary artery a prospective randomized comparison of gastroepiploic artery and saphenous vein grafts. J Am Coll Cardiol. 2008;51:120-5. 